\title{
Leaders of East European and Soviet communist parties, 1945-91
}

\section{Bulgaria}

1946-49

1949-54

1954-89

1989-90

\section{Czechoslovakia}

1929-53

1953-68

1968-69

1969-87

1987-89
Georgi Dimitrov

Valko Chervenkov

Todor Zhivkov

Petar Mladenov

Klement Gottwald

Antonín Novotný

Alexander Dubček

Gustáv Husák

Miloš Jakeš

1989 (November-December) Karel Urbánek

\section{East Germany (GDR)}

1946-71

1971-89

1989 (October-December)
Walter Ulbricht

Erich Honecker

Egon Krenz

Mátyás Rákosi

Ernö Gerö

János Kádár

Károly Grósz

Rezsö Nyers 


\section{Poland}

1943-48

Władysław Gomułka

1948-56

Bolesław Bierut

1956 (April-October)

Edward Ochab

1956-70

Wladysław Gomułka

1970-80

Edward Gierek

1980-81

Stanisław Kania

1981-89

Wojciech Jaruzelski

1989-90

Mieczysław Rakowski

\section{Romania}

1944-65

Gheorghe Gheorghiu-Dej

1965-89

Nicolae Ceauşescu

\section{USSR}

1928-53

Josef Stalin

1953-56

Interregnum 'collective leadership'

1956-64

Nikita Khrushchev

1964-82

Leonid Brezhnev

1982-84

Yuri Andropov

1984-85

Konstantin Chernenko

1985-91

Mikhail Gorbachev 